\title{
A PERSONAGEM FEMININA NO CONTO «AMOR» DE CLARICE LISPECTOR COMO UMA POSSÍVEL CHAVE PARA A INTERPRETAÇÃO COMPENDIADA DE TODA A SUA OBRA
}

\author{
Vlastimil Váně
}

\begin{abstract}
Analyzing the short story "Love" included in the collection Family Ties (1960) written by Brazilian writer Clarice Lispector we start from the structural analysis proposed by Affonso Romano de Sant'Anna. Then we focus, taking into account Herbert Marcuse's interpretation of Freud, on the female protagonist of the short story who is imprisoned in the patriarchal system, representing the desperate female condition in the society. As we consider this short story to be the exemplary one for all author's literary work, the present analysis tries to offer the general synthesis of its possible reading.

Keywords: Clarice Lispector; structure of the short story; female; patriarchy; psycho-analysis.

Resumo: Analisando o conto «Amor» da colectânea Laços de Família (1960) da escritora brasileira Clarice Lispector, partimos da análise estrutural oferecida por Affonso Romano de Sant'Anna. Logo nos debruçamos, apoiados numa interpretação filosófica do pensamento de Freud feita por Herbert Marcuse, sobre a personagem principal feminina do conto, aprisionada dentro do sistema patriarcal, mostrando a condição de impasse da mulher na sociedade. Considerando o conto exemplar da obra da autora tentamos dar ao mesmo tempo uma síntese geral da mesma.

Palavras-chave: Clarice Lispector; estrutura do conto; mulher; patriarcado; psicanálise.

Que esforço eu faço para ser eu mesma. Luto contra uma maré de mim.

Amar os outros é a única salvação individual que conheço: ninguém estará perdido se der amor e às vezes receber amor em troca.

Meu Deus, como o amor impede a morte! Não sei o que estou querendo dizer com isso: confio na minha incompreensão, que tem me dado vida instintiva e intuitiva, enquanto que a chamada compreensão é tão limitada.
\end{abstract}

(Clarice Lispector)

Nos estudos literários no Brasil dos últimos tempos os métodos de interpretar o texto através a contextualização histórico-social têm ganhado grande destaque e popularidade. De entre os pensadores, os representantes da Escola de Franfurkt servem da corrente 
referência; de entre os escritores mais examinados, talvez apenas uma mulher não deixe de perturbar os intérpretes. ${ }^{1}$

Defrontando-se, penosamente e com um profundo deleite ao mesmo tempo, na leitura mas também durante o ensino da literatura brasileira, com a obra rica, complexa e diversificada, de Clarice Lispector, este trabalho deseja expor, sintética e eclecticamente, embora sustentado por uma análise concreta, uma maneira de como compreender a produção clariciana, ciente dos riscos que corre, mormente no campo da simplificação demasiado redutora. Como um subproduto minúsculo ele também se propõe a oferecer uma breve lista de alguns textos críticos interessantes e convenientes sobre a escrita da autora.

\section{A estrutura do conto}

No livro Análise Estrutural de Romances Brasileiros, o poeta e crítico literário Affonso Romano de Sant'Anna detecta quatro passos básicos na estrutura das obras da escritora brasileira Clarice Lispector (1920-1977). A título de exemplo, serve-se do conto «Amor», texto que se pretende analisar também nestas linhas a seguir e que está incluído na colectânea Laços de Família (1960).

As quatro fases, que, via de regra, aparecem tanto nos romances quanto nos $\operatorname{contos}^{2}$ da autora, são:

1. Colocação do personagem numa determinada situação.

2. Preparação de um evento ou incidente discretamente pressentido.

3. Ocorrência do incidente ou evento. ${ }^{3}$

4. Desfecho em que se mostra ou se considera a situação do personagem após o evento ou incidente (Sant'Anna 1975: 190).

Dito de outra forma, resumidamente (cf. Lidmilová 1996: 181), Clarice põe o pratagonista numa situação-modelo num momento-limite, surgida de imprevisto devido a um moti-

\footnotetext{
1 Sem a indirecta orientação do prof. dr. Jaime Ginzburg da Faculdade de Filosofia, Letras e Ciências Humanas da Universidade de São Paulo, ocorrida no ano de 2007, este texto teria ficado ainda mais incompleto. Um exímio exemplo da linha crítica recém-mencionada é o seu estudo "Clarice Lispector e a razão antagônica» (2003), in: SCHMIDT, Rita Terezinha (org.), A ficção de Clarice: nas fronteiras do impossível, Porto Alegre: Editora Sagra Luzzatto, 85-99.

2 No entanto, convém tomar-se muita precaução ao aplicar esse esquema, já por si, necessariamente, uma abstracção, sobretudo para com os romances, se se quer evitar uma simplificação às vezes excessiva. Por exemplo, nos textos didáticos em voga (e comparando um com o outro quase invariáveis) Tempos da literatura brasileira e Clarice Lispector (Literatura Comentada), ambos de Benjamin Abdala Junior e Samira Youssef Campedelli, no contexto da estrutura quadrífida, põem o exemplo do romance A Paixão Segundo G. H. passando por cima do facto de que a narradora-protagonista «apenas» recorda, revive e reinventa o que lhe aconteceu no dia anterior e, além disso, de que os tempos e as acções de enunciado e de enunciação se alternam uns com os outros por vezes de modo imprevisível e até irreconhecível. Portanto a estrutura não truncada desse romance seria consideravelmente mais complexa mesmo que as quatro etapas contivesse óbvias também, ou melhor, mesmo que as quatro etapas desempenhassem papel fundamental na dada estrutura.

3 Benedito Nunes (1995: 84) une o segundo e o terceiro passo do esquema considerando-os um episódio único, «um momento de tensão conflitiva» que serve de núcleo à narrativa. No caso de «Amor», esse núcleo é «transe nauseante» (1995: 87). Tanto aquela quanto esta divisão podem lembrar a organização clássica duma estória qualquer em introdução, (conflito), clímax e desfecho; é conveniente, porém, não esquecer que aqui a atenção recai na vivência interior imediata do protagonista e em como esta é expressa, e não na acção ou aventura exteriores.
} 
vo insignificante, que muda radicalmente a sua sensação vital e a percepção do mundo ou que leva a uma reflexão metafísico-existencial.

Uma vez que a escritora não se preocupa substancialmente com os factos em si mas antes dá preferência à sua repercussão no indivíduo, como aliás afirma em vários depoimentos, ${ }^{4}$ parece bastante razoável na análise debruçarmo-nos com mais detalhe sobre o protagonista do conto em pauta que é, como na maioria dos textos de Clarice, uma personagem feminina. Outra razão para a escolha do tema é o empenho de sublinhar o papel da autora na literatura brasileira como sendo a primeira significativa voz que coloca permanentemente a imagem da condição de mulher na sociedade como uma questão básica.

Sendo o conto narrado cronologicamente na terceira pessoa do singular por um narrador omnisciente e à primeira vista impassível e objectivo, a estrutura geral proposta por Sant'Anna não se complica aqui e pode ser aplicada para toda a narrativa. Na práxis, os conteúdos das quatro fases são os seguintes:

1. A protagonista Ana, dona de casa no Rio de Janeiro, aparentemente sem ambições se não aquelas de ter a família contente, vai voltando de compras em um bonde, deixando o espírito divagar sobre a sua vida corriqueira.

2. Ana avista um cego mastigando goma que a prende metaforicamente com sua existência inquietante e põe-na em desequilíbrio com o mundo, enfatizado pelo derramar das suas compras; este efémero acidente torna-a violenta e involuntariamente diferente dos outros aos quais ela com sentimento de paz, segurança e anonimato anteriormente tinha pertencido.

3. Atónita com a situação inesperada (e para ela também desesperada e desesperante), Ana passa o seu ponto de descida e entra no Jardim Botânico cuja atmosfera envolvente a ajuda a sentir, perceber e pensar as coisas de maneira inabitual.

4. Ana volta a casa e às suas obrigações familiares, domésticas e quotidianas.

Para Affonso Romano de Sant'Anna, a mais importante dessas quatro unidades funcionais será a terceira já que nela ocorre a epifania e ele considera toda a obra narrativa de Clarice como uma escrita epifânica. ${ }^{5}$ Contudo, para as nossas finalidades da inspecção da protagonista as fases inicial e final do conto têm o mesmo relevo.

\section{A protagonista no início do conto}

O filósofo e sociólogo Herbert Marcuse (1898-1979), como bom, apesar de um tanto polémico representante da Escola de Frankfurt que é, procura unir profundamente, entre outras actividades intelectuais, a sociologia (ou a antropologia) e a psicanálise. No seu livro Eros e Civilização (original é de 1955), partindo do axioma freudiano segundo o qual a civilização se baseia na permanente subjugação dos instintos humanos ou, dito por outras palavras, a história do homem é a história da sua repressão (cf. 1999: 27 e 33), ele aproveita-se do conceito de Sigmund Freud sobre a constituição do sujeito em três principais camadas mentais, a saber, $i d$, ego e superego, para colocá-los no contexto da

4 Cf. por exemplo Abdala Jr. - Campedelli (1994: 271), ou Cadernos de literatura brasileira (2004: 62).

5 A esse respeito, além do texto de Sant'Anna, veja também p. ex. os livros de Olga de Sá A Escritura de Clarice Lispector (1979) e Clarice Lispector: A Travessia do Oposto (1993) ou um estudo comparativo «Três Momentos de uma Poética do Instante: A Escrtitura Epifânica em Guimarães Rosa, James Joyce e Clarice Lispector» de Zuzana Burianová, publicado no livro Portos flutuantes: Trânsitos ibero-afro-americanos (2004). 
sociedade em conflito. Uma das sociedades conflituosas par excellence é o patriarcado ${ }^{6}$ onde o $i d$ das mulheres é constantemente repremido pelos homens que criam as normas em vigor das quais se constitui o superego. E como o superego domina, mediante o ego, o $i d$, as mulheres obedecem a leis masculinas sem se dar conta disso, a miúdo, porque as repressões e restrições provenientes de normas cedo se tornam inconscientes, e por isso as leis se cumprem como se mecânica e automaticamente. ${ }^{7}$ É o que acontece também no conto «Amor».

Na sociedade patriarcal, hierarquizada, conservadora, preconceituosa, repressiva e autoritária, existem dois tipos básicos de mulher: ou se é esposa, ou se é «prostituta». Ser esposa significa ser aprisionada no lar doméstico, submissa, com o ego constantemente reprimido e por isso fragilizado, com funções de criada e procriadora. ${ }^{8}$ Ser «prostituta», neste contexto, não quer dizer obrigatoriamente ganhar dinheiro vendendo o seu corpo para fins sexuais mas tem o significado de possuir a liberdade, de não ser condenada à monogamia, enfim, de não ser subjugada aos homens. ${ }^{9}$

Ana do conto "Amor» é, dentro do patriarcado, uma mulher típica e normal. Mulher típica porque boa esposa e mãe, burguesa de classe média; normal porque se comporta conforme as normas, padrões da dada sociedade. O seu lugar é na cozinha. ${ }^{10} \mathrm{Na}$ aparente liberdade, desconhecendo outros modos de viver, o seu destino escolheu-o ela mesma, «ela plantara as sementes que tinha na mão» (Lispector 1998: 19). Por outro lado, o «destino de mulher» já tinha sido prescrito e ela viera a cair nele «com a surpresa de nele caber como se o tivesse inventado» (1998: 20). Sem sombra de dúvidas essa pacatez transigente é possível devido à educação recebida e à experiência ganha em contacto com o resto da sociedade no dia-a-dia.

A fortuna de cuidar do lar não preenche todo o tempo de Ana, ficam-lhe momentos vazios, da existência irrealizada, ressaltada em confronto com a vida activa dos seus próximos; em «certa hora da tarde as árvores que plantara riam dela» (1998: 19). Para evitar estes instantes «perigosos», bem conhecidos por ela, Ana vai entregando-se a novas e novas tarefas dignas de uma mulher casada, sufocando assim a sua identidade original («íntima desordem», «felicidade insuportável», 1998: 20) e os seus antigos anseios («o seu desejo vagamente artístico», 1998: 20). Para realçar a falta de liberdade nas

\footnotetext{
${ }_{6}$ De Freud resulta que todas as sociedades são repressivas e portanto existem nelas os seres humanos reprimidos, e os mais reprimidos são exactamente os mais fracos, os grupos minoritários como as crianças, os pobres, os velhos, os deficientes, as mulheres. Ligia Chiappini (2004: 264) ao comentar e aproximar o livro Brasilianische Fiktionen, gegenwart als pastiche de Ellen Spielmann explica que «em Clarice haveria uma nova descrição da vida privada, fazendo o privado tornar-se público e conseguindo assim espaço para os marginalizados, os outros, os subalternos. Nem heroína feminina nem escrita feminina (...), mas, sim, uma escrita que discute a possibilidade e impossibilidade do subalterno».

7 Cf. por exemplo Marcuse (1999: 37): «a repressão externa foi sempre apoiada pela repressão interna: o indivíduo escravizado introjeta seus senhores e suas ordens no próprio aparelho mental.»

8 As revistas femininas da época (neste caso, os anos 50 e 60 do século XX) definiram mulher ideal como carinhosa em casa (aliás, é ali onde se encontra o seu lugar certo) e austera na rua e cuja realização máxima está em um casamento bem-sucedido.

9 No conjunto da obra de Clarice, um belo exemplo da «prostituta» representa-o G. H. do romance A paixão segundo G. H., de 1964. Porém ali a emancipação da protagonista não se fundamenta primordialmente na sua liberdade sexual ou profissão livre (escultora) mas na sua independência económica.

${ }^{10}$ Cf. o trecho no estilo indirecto livre da leve reflexão de Ana no bonde sobre a sua vida: «(...) A cozinha era enfim espaçosa, o fogão enguiçado dava estouros. (...)» (Lispector 1998: 19). Ao lado dos membros da família é ela (a cozinha) a sua maior preocupação. Notem-se também as marcas do conformismo e da resignação de Ana: «enfim»e, no texto um pouco antes, «meia satisfação», e, um pouco depois, «tranqüilamente», e mais adiante «perplexamente», «para sempre» etc.
} 
opções (efectivamente, a inexistência das opções) e a passiva entrega de Ana ao sistema dominante, o narrador aproveita-se repetitivamente da frase de significado contrário, isto é, usa a figura de ironia: «Assim ela o quisera e escolhera.» (1998: 20 e 21, respectivamente). Além disso, nesta passagem o narrador põe-se solidariamente ao lado da personagem, no discurso que poderia ser o indirecto livre, e a repetição ganha a função de convencer o destinatário, que no plano da escrita é o leitor e no plano de solilóquio interior ou de fluxo de consciência é a própria personagem, de que o dito é verdade, para que $o$ aceite sem rebeldia.

Visto o ambiente da dominação e dominância masculinas em que o enredo do conto se desenvolve, resulta irónica a frase: «Parecia ter descoberto [Ana] que tudo era passível de aperfeiçoamento, a cada coisa se emprestaria uma aparência harmoniosa; a vida podia ser feita pela mão do homem.» (1998: 20). Como se com ela Ana pensasse: primeiro, com o casamento aperfeiçoei-me, o meu progresso é gradativamente positivo na medida em que evoluo de menina desenvolta a esposa severa; segundo, sou apenas uma coisa, um objecto nas mãos do homem, sem vontade própria, na subordinação completa ao outro; e terceiro, a minha existência harmoniosa é só aparência, a essência é diferente.

\section{A protagonista no momento da epifania ${ }^{11}$}

A essência de Ana, penosamente soterrada no fundo do seu ser, começa a emergir quando tem que enfrentar uma situação para a qual ela não estava em absoluto preparada. O único momento antes da epifania no qual Ana parece um ser humano autêntico é, paradoxalmente, aquele quando já parece ter sobrevivido o tempo temeroso e temível da tarde dos possíveis pensamentos e sensações perturbadores. ${ }^{12}$ De súbito, porém, surge o cego, ${ }^{13}$ o bonde dá uma arrancada, e «o mal estava feito» (1998: 22), a vida arrumada onde era «tudo feito de modo a que um dia se seguisse ao outro» (1998: 23) está altamente abalada. A partir daí, a autenticidade primordial volta timidamente a fazer parte de Ana, primeiro com «uma expressão de rosto, há muito não usada» que lhe ressurge «com dificuldade, ainda incerta, incompreensível» (1998: 22).

O choque acontecido causa em Ana o despertar do mundo há muito adormecido e esquecido nela, do universo no qual não sabe como (re)agir dado que as regras de comportamento apre(e)ndidas no seu velho mundo das aparências perdem a sua validez. E a incerteza leva à animosidade e ao mal-estar. Eis o momento da revelação, da epifania, quando as profundidades recônditas do eu e do mundo afloram à supefície, quando

11 «Nesses momentos de isolamento, não raro há um alargamento perceptivo e um espraiamento existencial por parte dos personagens, uma desautomatização da visão rotineira - que nem sempre se faz sem dor, mas que representa uma espécie de possibilidade de salvação existencial em meio à rotina de vida que passa sem se perceber», antecipamos com um resumo generalizado de Magalhães (2004: 302).

12 Cf. as duas frases seguintes: «Logo um vento mais úmido soprava anunciando, mais do que o fim da tarde, o fim da hora instável. Ana respirou profundamente e uma grande aceitação deu a seu rosto um ar de mulher.» (Lispector 1998: 21).

${ }^{13}$ Talvez não seja a cegueira do homem a causa do descarrilamento da protagonista mas a tomada da consciência da surpreendente auto-suficiência e independência dele, em contraste com os membros da família da Ana que precisam e exigem os seus cuidados (e/ou em contraste com ela mesma, dependente extrema da família). Porém principalmente será em razão da capacidade do cego de gozar a vida («mascar chicles») apesar da sua óbvia deficiência. Ao mesmo tempo, o cego desperta compaixão e evoca a fraqueza em oposição à brutalidade e à força do Jardim Botânico (as quais lembram a darwiniana lei do mais forte). Tanto o cego como a natureza, no conto, de facto, os representantes do mal, fazem que a protagonista se torna diferente, estranha, ou, dito de outra maneira, o encontro com o desconhecido (cego e natureza) aliena a protagonista da sociedade. 
a vivência se intensifica dramaticamente, quando a sensibilidade ameaça explodir. Neste momento, o tempo histórico e cronológico torna-se psicológico ou até atemporalidade. O objecto passa a ser sujeito e sai da uniformidade do mundo civilizado alienante com que entra em conflito. O confronto ou o relacionamento dialéctico entre o eu e o outro ${ }^{14}$ constitui o núcleo dramático não só das narrativas claricianas.

A nível da linguagem, ela torna-se mais lírica, no entanto, não acontece aquela contestação da linguagem padronizada, aquela dissolução do discurso convencional e por conseguinte aquela procura do novo código linguístico, fragmentário e tateante, de acordo com a nova experiência vivencial (perceptiva, sentimental e intelectual em decomposição) da personagem, dificilmente comunicável, como ocorre com frequência nas narrativas de Clarice em primeira pessoa do singular.

O novo estado de Ana, indesejável entretanto aprazível, expressa-se no texto por meio das figuras de oposição de significação ambígua, frequentes na obra clariciana, ${ }^{15}$ como a antítese, o paradoxo e o oximoro, por exemplo: «prazer intenso (...) sofrendo espantada», «uma bondade extremamente dolorosa», «náusea doce» (1998: todos 23). Mais adiante ainda lemos que «o Jardim era tão bonito que ela [Ana] teve medo do Inferno» (1998: 25) e que «amava com nojo» (1998: 26) ${ }^{16}$ Em determinado momento, Ana sente-se dilacerada entre o eu irracional e selvagem, que a leva à liberdade e à solidão, ${ }^{17} \mathrm{e} \mathrm{o}$ eu social e moral, que a orienta na vida; a antiga e aparente unidade dela como um todo harmonioso está destruída, a sua personalidade / integridade vai-se fragmentando. Ana chega a representar a imagem da mulher em impasse, devido ao desequilíbrio e à irreconciliabilidade entre as exigências dela e da sociedade.

A protagonista deixa-se dominar pelas sensações que a natureza brutal the tem sugerido $^{18}$ mesmo depois de acordada pela lembrança das crianças, também porque ela redescobre da mesma forma o fascinante mundo selvagem em casa. Ela perde a controle de si mesma, questiona os seus próprios valores. Por isso o reencontro com a família, isto é, com a sua vida antiga, o regresso ao respeito pleno do princípio de realidade, instituído em conformidade com a sociedade vigente inevitavelmente repressiva das liberdades individuais (dos não-escolhidos), não prescinde de desentendimento e confusão.

Retornando à teoria freudiana das três instâncias que compõem o aparelho psíquico, os momentos da epifania poderiam ser interpretados como uma aproximação da protagonista (do sujeito) do seu id. Se é certa a afirmação de Affonso Romano de Sant'Anna, apoiada nos depoimentos da própria escritora, que a criação dela parte de um processo intuitivo e inconsciente e baseia-se nele, a declaração feita na frase anterior torna-se mais aceitável já que o id é o império do inconsciente, dos impulsos e instintos primários. ${ }^{19}$

${ }^{14}$ Que pode ser também a união esquizofrénica dos dois eus adversários ou dificilmente compatíveis um com o outro.

15 Aliás, «os sentimentos ambivalentes e contrários (...) tomam conta do comportamento feminino» (SANTIAGO, Silviano, 2004, «Bestiário», in: AA. VV. Cadernos de literatura brasileira, n.os 17 e 18, Clarice Lispector, Instituto Moreira Salles, 210).

16 Yudith Rosenbaum (1999: 57), no capítulo sobre o conto «Os Desastres de Sofia», aludindo a Mal-estar na Civilização (1930) de Sigmund Freud, menciona que «o gozo é o mal, já que só é alcançado pela transgressão» e que o gozo, de facto, já consiste na transgressão. No entanto (e portanto), o gozo é uma expressão da liberdade que, por sua vez, se tende a limitar e a controlar.

17 A protagonista sente-se mais livre à medida que se sente só.

18 «Seu coração se enchera com a pior vontade de viver» (Lispector 1998: 27).

19 Yudith Rosenbaum (1999: 64) refere-se a essa revelação da vivência primária, a «essa experiência limite» como o retorno ao «cerne da vida, [a]o humus de onde tudo vem e para onde tudo retorna (...), [a]o núcleo do ser, 
A personagem feminina no conto «Amor» de Clarice Lispector...

\section{A protagonista no desfecho do conto}

Depois do torturante conflito interior, Ana de novo se insere naquela soturna «legião de pessoas, antes invisíveis, que viviam como quem trabalha - com persistência, continuidade, alegria ${ }^{20}$ (Lispector 1998: 20), ou seja, na sociedade burguesa, fora da «doença de vida» (1998: 20) da felicidade pré-adulta, fora da plenitude vital, fora do «perigo de viver» (1998: 29). O idílio burguês é salientado e ironizado na imagem da grande família ao redor da mesa: «Cansados do dia, felizes em não discordar, tão dispostos a não ver defeitos. Riam-se de tudo, com o coração bom e humano» (1998: 28). Coração bom e humano quer dizer coração controlado e civilizado. A tentativa da harmonia social, que se quer também no nível individual, vence as divergências e exigências pessoais íntimas.

No denso desfecho poético do conto o marido faz voltar literalmente mas talvez não definitivamente ${ }^{21}$ a protagonista ao seu mundo alienatório e ela, sem nenhuma luta, submete-se, deixa-se prender pelos «laços de família» convencionais e sobretudo fortemente restritivos. Ana aceita (por enquanto), depois da sua experiência recém-passada já conscientemente, a humanidade e as suas regras.

A expectativa da resposta concreta à pergunta o que é amor?, feita implicitamente no título do conto, é frustrada. No fim da narrativa, não chegamos a saber com certeza nem a quem o amor se dirige (à família?, a si próprio?, à vida?), nem como o amor é e deve ser. Essa ambiguidade inquietante traduz a precariedade e o impasse da personagem principal do conto e, de modo geral, de todo o universo ficcional de Clarice Lispector.

\section{Conclusão}

Os fecundos textos de Clarice Lispector oferecem-se a múltiplas e diferenciadas leituras, desde as estilísticas, existencialistas e psicanalistas até as feministas e histórico-contextuais, passando pelas estruturalistas e impressionistas. ${ }^{22}$ Não é nenhuma novidade que muitos desses métodos de análise literária até certo ponto se sobrepõem e completam. A tentativa de servir-se orgânica mas não rigorosamente de vários numa só abordagem um tanto sumária peca contra a metodologia pura e correcta, no entanto talvez possa advertir com melhor inteligibilidade e acessibilidade para a grande riqueza das obras da autora.

[a]o avesso da forma, [à] essência de onde tudo emana» e aponta a sua «afinidade com a dimensão do inconsciente». Mais adiante (1999: 65), a ensaísta, analizando «o processo de desvelamento do sujeito encoberto pelas máscaras» no conto «Os Desastres de Sofia», afirma que é «o pólo da impureza o modo de se aproximar do que já fomos um dia» e daí deduz que «a autora constrói uma 'estética do negativo' que aponta, em sua ironia, para a ruptura das ilusões convencionais». Anteriormente (1999: 54), ao se debruçar sobre a obscuridade do personagem do professor, Rosenbaum generaliza: «essa atração pelo malformado, pelo desconjuntado, pelo grotesco é traço profundo da obra clariciana e da arte moderna; ambas vêem na deformação recurso privilegiado para romper a moldura estética classicizante e lançar no leitor aquele 'foco de perturbação' de linhagem vanguardista.» Ou seja, contrapor a harmonia, ordem, objectividade, estabilidade, regularidade, racionalidade e beleza, o seu avesso; tanto na elaboração de personagens, como na construção de narrativa.

${ }^{20}$ Esta frase mais a anterior onde se diz que a Ana descobriu que também sem a felicidade se vive (cf. Lispector 1998: 20) sublinha a alienação civilizacional perante a liberdade individual.

${ }^{21}$ «O desfecho de 'Amor' deixa-nos entrever que o conflito apenas se apaziguou, voltando à latência de onde emergira» (Nunes 1995: 86). Pois a memória tem uma função específica «que é a de conservar as promessas e potencialidades que são traídas e até proscritas pelo indivíduo maduro, civilizado, mas que outrora foram satisfeitas, em seu passado remoto, e nunca inteiramente esquecidos» (Marcuse 1999: 39).

${ }^{22}$ Um bom resumo das várias e variadas leituras possíveis faculta já mencionada Ligia Chiappini (2004) no seu artigo. 
O conto «Amor» representa uma das narrativas curtas mais típicas de Clarice Lispector porque nela aparece a protagonista feminina em súbito conflito consigo mesma e com o seu rotineiro mundo quotidiano dado pelo seu status social, num momento que se costuma chamar epifânico e que se aproxima da descida arriscada ao id.

\title{
Bibliografia
}

Abdala Jr., Benjamin - Campadelli, Samira Youssef (1994), Tempos da Literatura Brasileira, São Paulo: Editora Ática.

AA. Vv. (2004), Cadernos de literatura brasileira, n. ${ }^{\text {os }} 17$ e 18, Clarice Lispector, Instituto Moreira Salles.

CAmpadelli, Samira Youssef - Abdala Jr., Benjamin (1988), Clarice Lispector (Literatura Comentada), São Paulo: Nova Cultural.

Chiappini, Ligia (2004), "Clarice e a Crítica: Por uma Perspectiva Integradora», in: POnTIERI, Regina (org.), Leitores e leituras de Clarice Lispector, São Paulo: Hedra, 235-268.

LiDMiLová, Pavla (1996), «Literární vtělování Clarice Lispectorové», in: LisPECTOR, Clarice, Tajné štěstí, Praha: Ivo Železný, 177-183.

Lispector, Clarice (1998), Laços de Família, Rio de Janeiro: Rocco.

Magalhães, Luiz Antonio Mousinho (2004), «Clarice Lispector fã de Chico Buarque», in: Fernandes, Rinaldo de, Chico Buarque do Brasil, Rio de Janeiro: Garamond/Fundação Biblioteca Nacional, 297-303.

MARcuse, Herbert (1999), Eros e Civilização (Uma Interpretação Filosófica do Pensamento de Freud), 8. ${ }^{\text {a }}$ ed., Rio de Janeiro: LTC Editora.

NunEs, Benedito (1995), «A forma do conto», in: O Drama da Linguagem: Uma leitura de Clarice Lispector, São Paulo: Ed. Ática, 83-95.

Rosenbaum, Yudith (1999), «Diabólica Inocência», in: Metamorfoses do Mal: Uma Leitura de Clarice Lispector, São Paulo: EDUSP / FAPESP, 51-67.

SAnt’Anna, Affonso Romano de (1975), «Laços de Família e Legião Estrangeira», in: Análise Estrutural de Romances Brasileiros, Petrópolis: Ed. Vozes, 180-212.

\author{
Vlastimil Váně \\ Ústav románských studií \\ Filozofická fakulta \\ Univerzita Karlova v Praze \\ Náměstí Jana Palacha 2 \\ 11000 Praha 1 \\ República Checa \\ vlastimil.vane@gmail.com
}

